\title{
Interactivity, Fictionality, and Incompleteness.
}

Nathan Wildman and Richard Woodward

At the end of Hidetaka Miyazaki's masterpiece Dark Souls, the player is faced with a choice: to link the flame and let the cycle continue, prolonging the Age of Fire, or to walk away and let the world fade to ash, ushering in the Age of Dark. This represents the culmination of a long and difficult journey that involves many other choices: where to go and in what order, who to kill and who to spare, and so on and so forth. Though many elements of the journey are fixed for all who battle to the end - the Bells of Awakening must be rung, for example - much is left up to the player.

Dark Souls, like most videogames, is plausibly classified as a work of fiction. ${ }^{1}$ This is reflected in the ease by which we apply to it the concept of fictionality, the concept of something being true "in" or "according to" a representational work. ${ }^{2}$ Even setting aside that the story of Dark Souls is opaque and open to interpretation, certain things are undoubtably true 'in the world of the story': for instance, it is true in Dark Souls that there are two Bells of Awakening (rather than twelve), that something (rather than nothing) happens when both Bells are rung, and that the fire is fading (rather than burning bright). Indeed, part of the richness of Dark Souls lies in the novel ways in which the fictional goings-on are indicated in indirect and subtle ways, via item descriptions, character design, and environmental clues, as opposed to the more direct methods often employed in other videogames.

Unlike more familiar works of literary fiction, however, there is something importantly interactive about Dark Souls. In part, this is because there seems to an important sense in which much of the story is, in one way or another, in the hands of the player. For instance, if the player enters the Painted World, they can choose whether to slay or spare Priscilla, and the player's choice seems to play a significant and essential role in shaping the content of the story itself: players who spare Priscilla make it fictional that she is spared, those who slay her make it fictional that she is slain. Put otherwise, Dark Souls leaves certain aspects of the story open, and it is up to the player to decide which path is taken, and hence what is fictionalized. This feature is further underscored by an important difference between the reasons why players repeatedly play through Dark Souls and why readers reread His Dark Materials. In both cases, our repeat engagement can be motivated by a desire to see what we have missed. But in the case of Dark Souls, our repeat engagement seems to

\footnotetext{
${ }^{1}$ Aarseth (2007) contends that videogames are virtual, rather than fictional. However, there is no obvious incompatibility between Aarseth's notion of virtuality and the notion of fictionality employed here.

${ }^{2}$ For an overview of the literature on fictionality, see Woodward $(2011,2014)$. We associate the idea that fictionality is distinctive of fiction with Walton (1990). For further discussion of the distinction between fiction and nonfiction, see Friend (2011), Stock (2011), Matravers (2014), and Davies (2015).
} 
be motivated by a desire to see how things can turn out differently if other choices are made (or to see how different choices ultimately deliver the same results).

We think these appearances are not deceptive: Dark Souls, like most videogames, can be rightly classified as an interactive fiction. ${ }^{3}$ That is, there is an important sense in which videogames like Dark Souls are interactive in ways that fictions from more traditional media are not. And one important aspect of this contrast arises out of the special role that players have in determining what is and what is not fictional.

The relevant notion of interactivity is unclear, however, standing in need of explication. And this lack of clarity isn't just a problem for understanding videogames. As the category of works of fiction can intuitively be taken as subcategory of the category of works of art, it is natural to think that the category of works of interactive fiction can be taken as a subcategory of the category of works of interactive art. But, despite the hype surrounding so-called interactive art, there is a mundane sense in which all artworks are interactive, since engagement and appreciation obviously require audience participation, from sheer attention to a subtler awareness of the contexts in which the relevant artwork was created and appreciated. To the extent that the label "interactive art" is not merely a buzzword, the idea must be that some (but only some) artworks have certain distinctive features the presence of which license the application of a more specific concept of interactivity not present in more traditional artworks. The question, then, is what those features that characterize the salient concept of interactivity are.

Dominic McIver Lopes (2001, 2010) offers a convenient starting point for addressing this question. Central to Lopes's proposal is a distinction between the structure of our experience of an artwork and the structure of that artwork itself. For instance, the structure of The White Album - that is, the intrinsic or representational features of the work "the appreciation of which are necessary for engagement with it" (2001, p. 68) - is not altered by shuffling the tracks. Similarly, the narrative structure of Noé's Irréversible, in which the order of narrated events differs from their chronological order, is not altered by the possibility of using a DVD to watch the chapters chronologically. In both cases, our experiences may vary depending on how we choose to engage with the target work, but the work itself remains unchanged.

With this in mind, Lopes distinguishes between weakly and strongly interactive works. According to him, a work is weakly interactive just in case appreciators of that work are in control of the order in which its content is presented to them. It should be clear that many, if not all, artworks turn out to be weakly interactive in this sense: we can read the chapters of 1984 , or listen to the tracks that

\footnotetext{
${ }^{3}$ In treating (most) videogames as interactive fictions, we follow e.g. Tavinor (2005, 2008, 2009), Robson and Meskin (2012, 2016), Meskin and Robson (2010, 2012) and Cova and Garcia (2015). The 'most' qualifier is necessary because plausibly some videogames - e.g. Tetris, Chessmaster, and Puzzle Bobble - are not fictions in the ordinary sense of the term, though they may be fictions in Walton's sense (see Walton 1990).
} 
make up The White Album, in any order we want, and even paintings like Guernica seem weakly interactive insofar as we have control over which part of the painting we examine first. But in these cases, the content of the work seems independent from the order in which we access it: though we have control over how we engage with the work, our choices have no effect on the nature of the work itself.

This marks the key feature of strongly interactive works: their content is "partially determined by the interactor's actions" (2001, p. 68). That is, the choices one makes when engaging with a strongly interactive work helps shape the very content of the work. Moreover, not only is the structure of a strongly interactive artwork shaped in part by the appreciators choices, but fully appreciating such an artwork also requires appreciating that the work is so-interactive (ibid, p.77). So whilst weakly interactive artworks may be malleable with respect to how we engage with their representational content, strongly interactive artworks are malleable in a more significant way.

Though some have qualms about its extensional adequacy, Lopes' proposal provides a highly suggestive model for understanding interactive fictions. ${ }^{4}$ Insofar as the structural properties of an interactive artwork are somehow determined by the choices of those appreciating that work, it is natural to think that interactive fictions are those fictions where the choices of appreciators play a constitutive role in determining what fictional, i.e. true according to that work. At the very least, the conception of interactivity wherein appreciators play a constitutive role in shaping what is fictional in ways beyond what is found in more traditional fictions is deserving of serious attention, apparently applicable with respect to videogames like Dark Souls, and dovetails with the wider discussion of the more general nature of interactive art. ${ }^{5}$ In this sense, it provides a plausible starting point for future exploration of the concept. What remains to be seen is whether the notion of interactivity can be further explicated in a way that coheres with our understanding of fictionality itself.

We believe that the key to doing so involves carefully distinguishing various ways in which fictions can 'leave things open'. For just as there seems to be a mundane sense in which all artworks are (weakly) interactive, there also seems to also be a rather mundane sense in which all fictions 'leave things open', since fictions seem to be essentially incomplete insofar as there are always questions about the fictional goings-on that are left open and unresolved. ${ }^{6}$ Properly understanding the contrast between interactive fictions like Dark Souls and non-interactive fictions like His Dark Materials, we will argue, involves the recognition of a particular kind of fictional incompleteness that is present in the former but not the later. The resulting

\footnotetext{
${ }^{4}$ See Smuts (2009) and Preston (2014).

${ }^{5}$ See e.g. Tavinor $(2005,2008,2009)$, Robson and Meskin (2012, 2016, 2017), and Patridge (2017) for similar thoughts.

${ }^{6}$ For further discussion about the essential incompleteness of fiction, see Wildman and Folde (2017, $\mathrm{ms})$.
} 
characterisation of interactivity via this specific type of fictional incompleteness will be useful not only to those who are interested in the nature and aesthetics of videogames, but also to those who interested in the more general notion of interactive art.

\section{Walton on Fictionality}

Though there is considerable debate about how the concept of fictionality should be understood, the dominant approach that can be found in the contemporary literature is due to the pioneering work of Kendall Walton in his Mimesis as Make-Believe. ${ }^{7}$ According to Walton, the key to understanding fictionality is to recognise that our engagement with fictions is both inherently imaginative and inherently structured.

That imagination plays a role in our engagement with fiction should not be surprising: Walton describes the idea as akin to pulling a rabbit out of a hutch. When we read a story like Harry Potter, we respond by imagining certain things: that there are wizards and witches, that there is a school called 'Hogwart's', that one young wizard who attends that school is called 'Harry' and so on. But, as Walton notes, our imaginative responses to a fiction are not chaotic: they are shaped by the objective features of the work in question (and perhaps wider features of the context of creation/appreciation). Thus central to his proposal is an analogy between truth and belief on the one hand, and fictionality and imagining on the other:

Imagining is easily thought of as a free, unregulated activity, subject to no constraints save whim, happenstance, and the obscure demands of the unconscious. In this respect, imagination appears to contrast sharply with belief. Beliefs, unlike imaginings, are correct or incorrect. Belief aims at truth. What is true and only what is true is to be believed. We are not free to believe as we please. We are free to imagine as we please. So it may seem, but it isn't quite so. Imaginings are constrained also; some are proper, appropriate in certain contexts, and others not. (1990, p.39)

So, for instance, just as we form beliefs with the goal of getting the world right, our imaginings are goal-directed too: loosely put, when we imagine things on the basis of engaging with a work of fiction, we want our imaginings to get its associated 'fictional world' right. Hence, just as there are tigers is the thing to believe in a context where there are tigers, there are witches is the thing to imagine in a context where one is reading a story in which it is fictional that there are such things.

However, in disanalogy to the case of belief, where it is natural to think that the question of whether $p$ is to be believed is fixed downstream of the question of whether or not $p$ is true - i.e. to the extent that one ought to believe that there are

\footnotetext{
${ }^{7}$ For a more detailed outline of Walton's account of fictionality, see Woodward (2014).
} 
tigers, that's because it is true that there are tigers - Walton thinks that fictionality can be analysed in terms of its normative role via the following definition:

What it is for $p$ to be fictional just is for there to be a prescription to imagine that $p^{8}$

Properly understanding this definition requires treading carefully. For one, the relevant claims of fictionality are work-relative: the proposition that there are witches is fictional with respect to Harry Potter but not to 1984, for instance. Hence the idea is that the fictionality of $p$ with respect to a work $w$ is tied to the existence of a prescription to imagine $p$ when one engages with $w$, and to the extent that the features of $w$ generate the prescription to imagine $p$, we might say that $p$ is $w$ fictional just in case $w$ prescribes imagining $p$.

Similarly, the relevant prescriptions are also goal-relative: if one engages with Harry Potter merely with the goal of examining J.K. Rowling's use of personal pronouns, there is no requirement that one imagines that there are witches since one is not engaging in a way connected to appreciating the work as a work of fiction. Thus the fictionality of $p$ with respect to a work $w$ is tied to the existence of a prescription to imagine $p$ when one engages with $w$ with the goal of fully appreciating that work.

Finally, it is important to note that the target concept of fictionality is operative with respect to questions of what is true according to a given work. That might sound trivial, but its importance emerges once it is remembered that there is another concept of fictionality that plays an important role in Walton's account, connected not to what is true according to a given work but rather to questions of what is true according to a game of make-believe. And, as we shall see in $\S 4$, tracing the connection between these two concepts will have a special significance for our discussion about the nature of interactive fictions.

\section{Fictional Incompleteness and Prescriptions (not) to Imagine}

Walton's account specifies not only the conditions under which a given proposition is fictional, but also the conditions under which a given proposition is not fictional: it is not the case that $p$ is fictional just in case there is no prescription to imagine that $p$. The phenomenon of fictional incompleteness thus emerges in cases where there is a gap in the imaginings prescribed by a work. To illustrate, consider a case in which a work is silent over some detail about a given character, such as the colour of that character's eyes. Such incompleteness is tied to the fact that it is neither fictional that

\footnotetext{
${ }^{8}$ Walton (2015) has distances himself from this proposal, and now takes prescriptions to imagine to be necessary but not sufficient for fictionality. See Woodward $(2014,2016)$ for a defence of the original proposal.
} 
the character has blue eyes, nor fictional that the character has green eyes, nor fictional that the character has brown eyes, and so on. But neither is it fictional that the character does not have blue eyes, nor fictional that the character does not have green eyes, nor fictional that the character does not have brown eyes, and so on. In each case, Walton's explanation is that there is a gap in the imaginings prescribed by the work. Hence the picture is one where a fiction is incomplete with respect to a given proposition $p$ just in case neither $p$ nor not- $p$ are fictional - which, for Walton, is explained in terms of there being neither a prescription to imagine $p$ nor a prescription to imagine not- $p$. (Note that in such cases the disjunction $p$ or not- $p$ may still be fictional, even though neither disjunct is.)

However, there is an important structural mismatch between the way we normally think about fictionality and the Waltonian account in terms of prescriptions to imagine. ${ }^{9}$ Fictionality is typically regimented in terms of fictional operators such as "it is fictional that", where the relativization to a work is left implicit, and "According to Harry Potter", where it is made explicit. However, when we consider how such operators interact with negation, it is clear that there are only three options: negation can take wide scope, as in "it is not fictional that $p$ ", narrow scope, as in "it is fictional that not-p", or both, as in "it is not fictional that not- $p$ ". All three cases are accommodated on Walton's account: the wide scope case emerges when there is no prescription to imagine $p$, the narrow scope case when there is a prescription to imagine not-p, and the both scope case when there is no prescription to imagine not-p.

But there is a further way negation can interact with prescriptions to imagine that has no obvious regimentation in terms of fictional operators, emerging whenever there is a prescription not to imagine $p$. Such prescriptions are different from the three cases considered above. That there is no prescription to imagine $p$ does not entail that there is a prescription not to imagine $p$, since the work may permit imagining $p$ even though it does not mandate doing so. For example, in Harry Potter, there is no prescription to imagine that Ron has an even number of freckles, but there is nothing preventing us from imagining that this is so: appreciators are permitted but not prescribed to imagine that Ron's freckles are evenly numbered. And that there is a prescription to imagine not- $p$ does not entail that there is a prescription not to imagine $p$, since the work may be inconsistent, mandating imagining both $p$ and not- $p$. Finally, that there is no prescription to imagine not- $p$ does not entail that there is a prescription not to imagine $p$ since one reason why a work may not prescribe imagining not- $p$ is because it rather prescribes imagining $p$. For instance, the reason why it would be a mistake to imagine that Hermione is not a witch is precisely because she is one.

These observations help to clarify the notion of fictional incompleteness. For even if the general specification of fictional incompleteness is given in terms of it

\footnotetext{
${ }^{9}$ The following observations are explored in more detail in Williams and Woodward (ms).
} 
neither being fictional that $p$ nor fictional that not- $p$, and even if that condition obtains whenever there is neither a prescription to imagine $p$ nor a prescription to imagine not- $p$, there are (at least) two very different species of fictional incompleteness that can be a distinguished. On the one hand, we have cases where there is not only no prescription to imagine $p$ and no prescription to imagine not- $p$, but also no prescription not to imagine $\mathrm{p}$ and no prescription not to imagine not-p. Put otherwise, in such cases, imagining $p$ and imagining not- $p$ are both permitted, though neither is prescribed. (We assume, in line with the standard literature on deontic modals, that permission is the dual of obligation.) On the other hand, there will be cases where there is no prescription to imagine $p$ and no prescription to imagine not- $p$, though there is also a prescription not to imagine $\mathrm{p}$ and a prescription not to imagine not- $p$. In these cases, imagining $p$ and imagining not- $p$ are not merely not required, but in fact prohibited. Accordingly, call the former cases of permissive incompleteness, and the latter cases of prohibitive incompleteness.

Standard instances of fictional incompleteness, which arise due to fictions being silent over details inessential to appreciating the work, are naturally classified as permissive cases. Imaging Ron as having an even number of freckles even though the work is itself silent over the matter seems acceptable; in Walton's terminology, such imaginings are authorised by Harry Potter, even though the imaginings have gone beyond what are, strictly speaking, prescribed by the work.

However, there are cases which more plausible fit the prohibitive model. Consider the question of whether Bladerunner's Rick Deckhard is a human being or a non-human replicant. Unlike a "don't care" question (e.g., does he have an even number of freckles?), whether Deckhard is a human or replicant lies at the very heart of the film, such that fully appreciating Bladerunner may be thought to require being in a state of imaginative uncertainty about his true nature, to suspend making an imaginative judgement one way or the other. Put otherwise, fully embracing the ambiguity of Bladerunner involves playing a game of make believe which does not settle whether or not Deckhard is human. ${ }^{10}$

Finally, recall that Walton's starting point for building his account is the analogy between the link between belief and truth on the one hand and between imagining and fictionality on the other. That analogy is again suggestive: if there is a gap in what is true (perhaps due to vagueness or the openness of the future, say) we should not conclude that it is always permissible to believe whatever we wish; in

\footnotetext{
${ }^{10}$ Our take on the Bladerunner case is, admittedly, controversial: whereas its director, Ridley Scott, has said that Deckhard is an replicant, Philip K. Dick, the author of the story of which it is based, has said that Deckhard is human (and this is how Harrison Ford said he played Deckard in Bladerunner). And there is also a tricky question of how our interpretation of Bladerunner will be effected when its upcoming sequel is released. For our part, we do not think that the beliefs of fiction makers decisively settle questions of what is true according to the work's they create: considerations of aesthetic charity also play an important role. And Bladerunner is better if interpreted along the lines we have described. For more on the factors relevant to the determination of fictionality, see Woodward (2014, pp.832-5).
} 
such cases we are required to suspend belief. Similarly, if there is a gap in what is fictional, we should not conclude that it is always permissible to imagine whatever we wish; in some cases, we should suspend imaginative judgement.

Now, recall that one of our central goals is to make sense of the idea that interactive fictions are distinctive insofar as the choices of appreciators play a constitutive role in determining what is and what is not true in the story in ways that go beyond what is found in more traditional, non-interactive works. Our previous discussion of fictional incompleteness is an important step insofar as it gives precise content to the thought that fictions leave things open. That is, to say that a fiction leaves it open whether $p$ (e.g. that Harry Potter leaves it open whether Harry's blood type is $\mathrm{A}+$, or that Blade Runner leave it open whether Deckhard is a replicant) is to say that it is not the case that $p$ is fictional but also that it is not the case that not- $p$ is fictional (e.g. that it is neither fictionally true nor fictionally false that Harry's blood type is $A+$, and neither fictionally true nor fictionally false that Deckhard is a replicant). This general characterisation of fictional incompleteness, moreover, allows for two more specific cases within the context of Walton's conception of fictionality: the case where appreciators are permitted to respond to a case of fictional incompleteness by imagining what they want, and the case where appreciators are not permitted to respond by imagining what they want.

Of course, the phenomenon of fictional incompleteness is ubiquitous, and by no means restricted to interactive fictions: Harry Potter and Bladerunner are just as incomplete as Dark Souls. So, if we are to make the case that there is a kind of fictional incompleteness that is distinctive of interactive fictions, we must established is that there is a further kind of fictional incompleteness, beyond the permissive and prohibitive cases, and that the presence of this kind of fictional incompleteness is the hallmark of interactive fictions.

\section{Works, Games, and Choices}

According to Walton, when we engage with representational artworks - "fictions", in his sense - we engage in sophisticated games of make-believe, much like the games played during childhood (cops and robbers, bears, etc.). In light of our previous discussion, this analogy should not be too surprising, since our engagement with children's games, like our engagement with fictions, is both imaginative, in the sense that playing the game involves imagining that certain things are the case, and structured, in the sense that there are oftentimes rules which determine what is to be imagined (e.g. the players of a game might be prescribed to imagine that $x$ is dead if, in reality, $x$ is lying motionless on the ground, or the players might be prescribed to imagine that $x$ is a bear if, in reality, $x$ is a tree stump). We devote much time and energy to playing such games of make-believe during our childhood years, and it would be surprising if the urge to engage in such games disappeared without a trace in adulthood (especially given the important roles that 
such games play). According to Walton, this urge instead re-manifests itself in our engagement with fiction.

However, in the case of fiction, there is a distinction between what is true in the work and what is true in the game of make-believe we play with that work. That is, there is a concept of fictionality defined in terms of the existence of prescriptions to imagine that is operative with respect to questions of what is true according to a given work. But there is another concept of fictionality connected to questions of what is true according to a given game of make-believe. ${ }^{11}$

And it is crucial to see that there is no simple one-to-one correlation between works and their associated games. It is perfectly possible, e.g. that two people could read Harry Potter but play different games of make-believe as a result: Billy could play a game according to which Harry is an evil child and Alice could play a game according to which Harry is a good child. Then even though their games of makebelieve are tied to the same work of fiction, they are distinct insofar as they have different contents that are generated on the basis of different principles of generation. But not all games of make-believe are born equal: there is clearly some sense in which Billy is playing the wrong game and Alice is playing the right one. Or, to use the nomenclature that Walton introduces, Billy is playing a game that is authorized for Harry Potter, whereas Alice is playing a game that is unauthorized.

The distinction between what is true in a work of fiction and what is true in a game of make-believe has a special relevance in the context of fictional incompleteness. For suppose that Alice is not only playing a game in which Harry is good, but also one in which Harry has A+ blood. (For instance, suppose Alice has the bizarre belief that all good children have type $\mathrm{A}+$ blood, and comes to imagine that Harry has A+ blood on the basis of imagining that Harry is a good child.) Then though it is neither true in the work nor false in the work that Harry has type A+ blood, it is still true in Alice's game that Harry has A+ blood: it is something she should imagine on the basis of the principles of generation she accepts. And assuming that this is a case of permissive incompleteness, it follows that her game is authorised for Harry Potter even though there is something true in her game that is not true in the work that is Harry Potter.

In cases of permissive incompleteness, then, it is allowed that a game of make-believe can be authorised even though it is more complete than the work: though $p$ will be neither fictionally true nor fictionally false, we allow that $p$ can be true in some authorised games and false in other authorised games.

By contrast, in cases of prohibitive incompleteness, it is not only the work that is incomplete: since appreciators are prohibited for imagining one way or the other, there will be no authorised game in which $p$ is true and no authorised game in which

\footnotetext{
${ }^{11}$ Compare Walton's (1978, pp.10-11) distinction between imaginary fictional truths and make-believe fictional truths. The relation between that distinction and the one drawn by Walton (1990) is somewhat unclear, and we will take the later as canonical.
} 
not- $p$ is true. So each individual game authorised for the work in question will be incomplete with respect to $p$. If Alice were to play a game in which she imagined that Deckhard was human or that he was not human (but rather a replicant), she would not be playing an authorized game, since, in both cases, there would be something that is true in her game that is not true in any game authorised for Blade Runner.

With these distinctions in mind, we can finally turn to the kind of incompleteness found in Dark Souls - and by extension, other interactive fictions. In one sense, the incompleteness in Dark Souls is permissive in character: it may not be true in Dark Souls that the player character links the fire rather than lets it fade, but players are permitted to choose to link the fire, and permitted to choose to let the world fade to ash. However, in another sense, the incompleteness in Dark Souls is very different to the cases of permissive incompleteness that we have considered so far. One way to see this is to note that if the player character does not make a choice - perhaps when faced with the burden of deciding the fate of the Lordran, they just quit and play something less onerous - then there is a clear sense in which they stop engaging with the work. In other words, full appreciation of Dark Souls requires that the player resolves the incompleteness. ${ }^{12}$ Nothing like this is true of the cases of permissive incompleteness we have considered; in those, appreciators are allowed to resolve the incompleteness as they see fit, though the work does not force them to resolve the incompleteness. Hence, whilst the kind of incompleteness we find in Dark Souls is permissive in the sense that the player is permitted to resolve the worklevel incompleteness in a variety of ways, it differs from standard cases of permissive incompleteness by also being prescriptive, in the sense that the player is not only permitted but prescribed to resolve the incompleteness in some way (though there is no particular resolution that is so-prescribed).

The contrast between these cases can be precisely modelled within the Waltonian conception of fictionality. Whilst Alice is permitted to imagine that Harry has blood type A+ and permitted to imagine that Harry has some other blood type, she is not required to imagine one way or the other. That is, though there are authorised games in which Harry has blood type A+, and authorised games in which Harry has some other blood type, there are also authorised games that are incomplete with respect to Harry's blood type (though it might be true in such games that he either does or doesn't have A+ blood). Meanwhile, though the player of Dark Souls is permitted to link the flame and permitted to let the fire fade, she is required to go one way or the other. That is, whilst there are games of make-believe that are authorised for Dark Souls in which the Chosen Undead (the player-character)

\footnotetext{
${ }^{12}$ Note that if the player resolves the incompleteness by (say) linking the fire, it will no longer be permissible to imagine that the fire fades to ash. What is going on here is that the permission to imagine that $p$ is co-ordinated with a conditional obligation: if the player chooses to link the fire rather than letting it fade to ash (as she is permitted to do), then she will be obliged to imagine that the fire gets linked and doesn't instead fade to ash.
} 
links the flame and other authorised games in which the Chosen Undead lets the fire fade, there are no authorised games in which the Chosen Undead neither links the flame nor lets the fire fade.

Moreover, the kind of incompleteness found in Dark Souls and other interactive fictions differs from more familiar kinds of incompleteness in another way. For instance, in normal cases of permissive incompleteness, the appreciator may resolve the incompleteness simply by imagining one way rather than the other; it is true in Alice's game that Ron has an even number of freckles simply because that is how Alice imagines Ron. But in the case of Dark Souls, resolving the incompleteness is accomplished by the player's doing something more - i.e., inputting certain commands at the relevant point - which makes it true in her game that the fire is linked. In other words, it is not true in Isabel's game that the fire is linked simply because that is what she imagines. Rather, it is true in her game that the fire is linked because she exploits the media-specific mechanisms (command inputs) that ensure that it is true in her game that the fire is linked. ${ }^{13}$ And note that it will be true in her game that the fire is linked even if she doesn't imagine it to be linked. If she inputs the relevant command and then becomes distracted by her cat, it will be nonetheless true in her game that the fire is linked even though she doesn't imagine it. The commands she inputs make it the case that linking the fire is the thing that is now prescribed to be imagined, whether or not she does indeed imagine that the fire is linked.

In this sense, the kind of incompleteness found in Dark Souls differs from standard cases of incompleteness in two ways: (a) the appreciator is not only merely permitted, but in fact required to resolve the incompleteness, and (b) the specific mechanisms (i.e. media-specific principles of generation) by which the incompleteness is resolved are distinctive.

\section{§5. Interactivity as Incompleteness}

The form of incompleteness found in Dark Souls and other interactive fictions is an instance of forced choice incompleteness:

\section{Forced Choice Incompleteness}

A work is forced choice incomplete with respect to $p$ just in case (a) there is no prescription to imagine $p$ and no prescription to imagine not- $p$ (i.e. $p$ is neither fictionally true nor fictionally false) and (b) there is a prescription to either imagine $p$ or imagine not- $p$

\footnotetext{
${ }^{13}$ For different media, this will take different forms: for example, this will mostly involve the use of controllers in videogames, but will consist of turning to a specific page in the case of CYOA books.
} 
Understanding the second clause is crucial here. To say that there is a prescription to either imagine $p$ or imagine not- $p$ is not to say that there is a prescription to imagine the disjunction, $p$ or not- $p$. One does not comply with the prescription to either imagine $p$ or imagine not- $p$ by imagining a disjunction: one complies with it by imagining one of the disjuncts. And though there is no requirement to imagine one disjunct rather than the other, there is a requirement to either imagine one disjunct or to instead imagine the other. More generally, all cases of forced choice incompleteness will be cases of permissive incompleteness (since there cannot be a prescription of either imagine $p$ or imagine not- $p$ if there are prohibitions on imagining $p$ and imagining not- $p$ ), though not all cases of permissive incompleteness will be cases of forced choice incompleteness (since it might be not only permitted to imagine $p$ and permitted to imagine not $p$ but also permitted not to imagine $p$ and permitted not to imagine not- $p$ ).

The concept of forced choice incompleteness, we submit, allows for the demarcation of a kind of incompleteness that sheds new light on our understanding of interactive fictions. In particular, it allows us to address the puzzling question of how we can reconcile the idea that interactive fictions leave certain questions about the fictional goings-on open, whilst at the same time allowing that, in a given interaction, the fictional goings-on are settled by the choices made by the appreciator. By holding that interactive fictions generate cases of forced choice fictional incompleteness, we can have our cake and eat it. Interactive fictions leave questions of fictionality open by generating cases of fictional incompleteness. And the fictional goings-on are settled by choices made by the appreciator because all games of makebelieve that are authorised for that work will resolve the target incompleteness in one way or the other. They are genuine cases of incompleteness since there is no prescription to imagine one way rather than the other, though, but since there is a prescription to imagine one way or the other, they also share a feature that is typically only found in cases of fictional completeness. That is, in cases of forced choice incompleteness, there is a prescription to imagine, though there is no particularly imagining that is so-prescribed.

Our proposal also gives a natural explication of the intuition that interactive fictions are distinctive insofar as their content is determined by the choices and decisions of appreciators in ways that go beyond what is found in traditional fictions, i.e. that interactive fictions leave things open and require appreciators to decide how things will turn out. In this way, it nicely extends and clarifies Lopes' notion of (strong) interactivity by linking it to a developed notion of fictionality.

And, as should be clear, what counts as interactive fictions in our sense isn't just limited to videogames like Dark Souls: 'Choose Your Own Adventure' stories (tellingly also known as gamebooks) like Edward Packard's The Cave of Time, instances of live-action and table-top role-playing games, like playings of Dungeons and Dragons and Gloomhaven, and "interactive movies" such as Kinoautomat in which readers/players/viewers are required to make choices that determine the fictional goings-on will also generate cases of forced choice incompleteness. However, the 
kind of incompleteness we are propose to take as the hallmark of interactive fictions is plausibly not found in works of traditional, non-interactive fiction. In this way, it is distinctive of genuinely interactive fictions.

\section{Incompleteness and Genre Classification}

Before concluding, we would like to anticipate one objection that might be raised against us. Specifically, one might object that forced choice incompleteness is not distinctive of interactive fiction since it is found in a particular range of traditional fictions, viz. those that are incomplete with respect to matters of genre classification.

There is a long-running critical dispute over the interpretation of William James' The Turn of the Screw, which can be read either as a naturalistic tale of a governess who hallucinates spirits threatening her charges or as a supernatural story of a woman genuinely being haunted by malicious ghosts. Both readings seem to comport with the fictional goings on, though how we classify the story with respect to its genre greatly impacts what is and is not fictional. For example, if we take it to be a ghost story, then it is fictional that there are ghosts that the Governess sees, which will not be the case if we classify it differently. In this way, Turn of the Screw is genre incomplete in the sense that it is left open into which genre the work is to be classified.

This genre incompleteness entails that Turn is incomplete with respect to the proposition that there are ghosts: this proposition will be fictionalised if we read Turn as a ghost story, its negation being fictionalised if we read James's work as a naturalistic story. As neither genre classification is prescribed, there is no prescription to imagine that there are ghosts, nor a prescription to imagine that there are no ghosts. Further, one might think that readers are not only permitted to read James' work in either way, while also being required to read the work one way or the other, which entails that they are required to either (classify it as a ghost story and) imagine that there are ghosts or instead (classify it as a naturalistic tale and) imagine that there are no ghosts. And this looks problematic for our claim that forced choice incompleteness is characteristic of interactive fictions. For The Turn of the Screw, like other genre incomplete fictions, is intuitively a traditional and noninteractive fiction. Consequently, our proposal appears to mistakenly classify some paradigmatically non-interactive fictions as interactive.

In response, first note that the availability of multiple interpretations only generates genuine fictional incompleteness if we assume that the interpretations (and the genre classifications on which they are based) are all equally legitimate. After all, that it is possible to (mis)read The Maltese Falcon as a ghost story doesn't entail that it is incomplete with respect to ghosts; rather, such an interpretation is simply not authorised for the work. It is not implausible that The Turn of the Screw is similar: arguably James did not intend the work as anything other than a ghost story and, at least to the extent that authorial intention plays an important role in determining how a work should be understood and interpreted, that gives us a 
reason to resist the claim that the work is incomplete with the respect to the existence of ghosts.

Moreover, it is not obvious that genre incompleteness entails forced choice incompleteness, since the fictional incompleteness generated by cases of genre incompleteness might naturally be classified in other ways. For instance, one of the main worries about simply classifying Turn as a ghost story and dismissing all other interpretations as illegitimate is that doing so seems to miss one of the most aesthetically interesting features of the work, viz. the way in which the work is elegantly ambiguous, poised between interpretations. Indeed, one might think that the kind of incompleteness generated by Turn is actually akin to that of Bladerunner: that is, rather than being prescribed to make a choice between two competing and mutually inconsistent options - i.e. a choice between playing a game which resolves the incompleteness one way or the other - fully appreciating the work requires not making a choice, and being in a state where one's imaginative responses are carefully poised between the competing options. So understood, the incompleteness generated by The Turn of the Screw would be prohibitive rather than permissive, and thereby very different from the kind of incompleteness we have associated with interactive fictions.

Similarly, the option of not resolving the incompleteness seems permitted by Turn. This means that the kind of fictional incompleteness generated by genre ambiguous works is not best understood terms of the binary choice of either classifying the story as an instance of one genre (ghost story) and thereby imagining $p$ (that there are ghosts) or instead of classifying the story as an instance of another genre (naturalistic story) and thereby imagining not- $p$ (that there are no ghosts). There is in fact a third option - which is certainly permitted and might even be prescribed - of letting one's imaginings be poised between the two options by simply not imagining either way. In this way, the kind of fictional incompleteness generated by cases of genre incompleteness will be distinct from the kind of incompleteness that we have associated with interactive fictions, where full appreciation requires making a binary choice.

In sum: the present objection assumes that the kind of fictional incompleteness generated by cases of genre incompleteness is an example of forced choice incompleteness, where appreciators are required to make a binary choice between two competing genre classifications, and in turn between imagining one proposition or instead imagining its negation. Our reply is that the kind of fictional incompleteness generated by genre incompleteness is not best understood in this way, since it robs genre incomplete works of their most distinctive feature, viz. their inherent ambiguity. ${ }^{14}$

\footnotetext{
${ }^{14}$ We would like to thank Amanda Cawston, Christian Folde, Stacie Friend, Aaron Meskin, Robbie Williams, the audience at the Just A Game? conference at the University of Kent, and the editors of this volume for helpful discussion and feedback at various stages of development. We gratefully
} 


\section{References}

Aarseth, Espen. 2007. 'Doors and Perception: Fiction vs. Simulation in Games.' Intermediality: History and Theory of the Arts, Literature and Technologies 9: 35-44.

Carroll, Noël. 1994. 'The Paradox of Junk Fiction'. Philosophy and Literature 18 (2): 225-241.

Cova, Florian, and Amanda Garcia. 2015. 'The Puzzle of Multiple Endings.' The Journal of Aesthetics and Art Criticism 73: 105-114.

Davies, David. 2015. 'Fictive Utterance and the Fictionality of Narrative and Works'. British Journal of Aesthetics 55: 39-55.

Friend, Stacie. 2012. 'Fiction as a Genre'. Proceedings of the Aristotelian Society 112: 179209.

- 2017. 'The Real Foundation of Fictional Worlds', Australasian Journal of Philosophy 95: 29-42.

Lopes, Dominic McIver. 2001. 'The Ontology of Interactive Art.' Journal of Aesthetic Education 35: 65-81.

- 2010. A Philosophy of Computer Art. London and New York: Routledge.

Matravers, Derek (2014). Fiction and Narrative. Oxford: Oxford University Press.

Meskin, Aaron, and Jon Robson. 2010. 'Videogames and the Moving Image.' Revue Internationale de Philosophie 64: 547-564.

- 2012. 'Fiction and Fictional Worlds in Videogames'. In The Philosophy of Computer Games, edited by John Richard Sageng, Tarjei Mandt Larsen, and Hallvard Fossheim, 201-217. Dordrecht: Springer.

Patridge, Stephanie. 2017. 'Videogames and Imaginative Identification'. Journal of Aesthetics and Art Criticism 75 (2):181-184.

Preston, Dominic. 2014. 'Some Ontology of Interactive Art'. Philosophy and Technology 27 (2): 267-278.

Robson, Jon and Aaron Meskin. 2012. 'Videogames and the First Person'. In Mimesis: Metaphysics, Cognition, Pragmatics, edited by Gregory Currie, Petr Kotako, and Martin Pokorny, 435-464. London: College Publications.

- 2016. 'Videogames as Self-Involving Interactive Fictions.' The Journal of Aesthetics and Art Criticism 74 (2): 165-77.

- 2017. 'Still Self-Involved: A Reply to Patridge'. Journal of Aesthetics and Art Criticism 75 (2):184-187.

Smuts, Aaron. 2009. 'What is Interactivity?' Journal of Aesthetic Education 43: 53-73.

Stock, Kathleen. (2013). 'Imagination and Fiction: Some Issues'. Philosophy Compass 8: 867-896.

Tavinor, Grant. 2005. 'Videogames and Interactive Fiction.' Philosophy and Literature 29: 24-40.

acknowledged the support of the Deutsche Forschungsgemeinschaft via the DFG Emmy Noether Research Group Ontology after Quine (University of Hamburg, WO 1896/1-1). 
- 2008. 'Definition of Videogames'. Contemporary Aesthetics 6: http://hdl.handle.net/2027/spo.7523862.0006.016

- 2009. The Art of Videogames. Oxford: Wiley-Blackwell.

Walton, Kendall L. 1978. 'Fearing Fictions'. The Journal of Philosophy 75: 5-27.

- 1990. Mimesis as Make-Believe: On the Foundations of the Representational Arts. Harvard University Press.

- 2015. 'Fictionality and Imagination: Mind the Gap!' in his In Other Shoes, 17-35. Oxford: Oxford University Press.

Wildman, Nathan and Christian Folde. 2017. 'Fiction Unlimited'. Journal of Aesthetics and Art Criticism 75 (1): 73-80.

- MS. 'Outer Limits: the bounds of fictional truth'. (Unpublished manuscript)

Williams, J. Robert G. and Richard Woodward. MS. 'The Cognitive Role of Fictionality'. (Unpublished Manuscript)

Woodward, Richard. 2011. 'Truth in Fiction'. Philosophy Compass 6: 158-167.

- 2014. 'Walton on Fictionality'. Philosophy Compass 9: 825-836.

- 2016. 'Fictionality and Photography'. Journal of Aesthetics and Art Criticism 74: 279-289. 